\title{
Juniperus polycarpos K. Koch (Turkestan Juniper) Species in Turianchai Preserve (Azerbaijan Republic)
}

\author{
E. M. Gurbanov, Z. C.Mamedova and A. A. Rzaeva \\ Baku State University, Baki AZ1000 Azerbaijan
}

\begin{abstract}
Juniper is one of the most useful multi-purpose plants worldwide. Containing a large number of essential oil, extracts from its leaves and berries (the blue-black seed cones) have been used as traditional medicine against urinary infections, dermatitis or as a diuretic. Juniperus polycarpos K. Koch is an important element of the rare pistachio-juniper thin forests [1, 2]. Habitat fragmentation and low regeneration are the main reasons of conservation Juniperus populations in this region. In order to prevent a decline in its area, mostly caused by problems in natural regeneration, the present study was carried out to analyze of Juniperus polycarpos individuals in Turianchai preserve. The bio-morphological analysis and age stages description is very consequential in order to protect this main member of dry arid forests of Azerbaijan.
\end{abstract}

Key words: Juniperus polycarpos, Turianchai preserve.

\section{Introduction}

Turianchai Preserve is located in the foothills of the Major Caucasus on the slopes of the Bozdag Range in Agdash region. Within the preserve, the Bozdag Range is divided longitudinally by the Turianchai River, which flows from the Greater Caucasus.

This preserve was organized in 1958 to safeguard the rare pistachio-Juniper thin forests. Juniperus polycarpos K. Koch belongs to the family cupressaceae and can be met mostly in mild and subtropical areas. Juniper has a significant place in folklore for its diverse ethno botanical, medical, veterinary and culinary uses. Mainly, juniper can grow in a wide range of soil types at varying altitudes, but it favors free draining soils and rarely inhabits wet conditions $[3,4]$. Caused by their potential to grow under the hard conditions, junipers are particularly suited for afforestation programs in various ecological areas [5]. Mainly, this species has expanded in opulence and habitat range with some fluctuations based on naturally and man caused fires. Most of

Corresponding author: Jorge Octavio Virues Delgadillo, professor, research fields: food rheology and biomaterials mechanical testing. juniperus species has rapidly self-reestablishment ability [6, 7, 8]. Reestablishment in before occupied areas and additionally spread into new areas is a progressing process especially in the lack of regular fire. The comprehensive study of junipers biomorphology and ecology is indispensable for better appreciation of the difference in abundance of this species, its impact on ecosystem structure and function.

\section{Materials and Methods}

In 2015-2017, we have visited 11 populations of Juniperus polycarpos located in medium arid forests of Turianchai preserve [Fig 1.]. Trip observations were carried out to estimate age structure of juniperus populations in this region. The area of observations was between $40^{\circ} 46^{\prime} \mathrm{N}$ and $47^{\circ} 24^{\prime}$ E. Observed trees were selected from relatively far localized associations. Soil types of Turianchai preserve are mainly black-brown and brown forest soils. Bio-morphological analysis conducted was in accordance with the system of independent morphological units of L. Gatcuk. Within the life period the following groups are distinguished to: 
established seedling, juvenile, reproductive adult and senescent. Fifty examples of Juniperus polycarpos have been studied and their age stages were described. In age stage identifications visual tree assessment methods have been used.

\section{Results}

Fifty examples of Juniperus polycarpos have been studied in Turianchai preserve, their bio-morphological stages were identified visually by observations. All observed locations were consisted of isolated minor groups or single plants. This tendency shows the importance of their protection.

We have determined the age structure by allocating each individual to one of the following age categories: established seedling, juvenile, reproductive adult and senescent. We contemplated each age class to correspond, appropriately, to the size categories of

Table 1 Age structure of Juniperus polycarpos in Turianchai preserve.

\begin{tabular}{lll}
\hline Age groups & Number of shrubs & Percentage \\
\hline Habitual seedling & 5 & 10 \\
Juvenile & 19 & 38 \\
Reproductive adult & 25 & 50 \\
Senescent & 1 & 2 \\
\hline
\end{tabular}

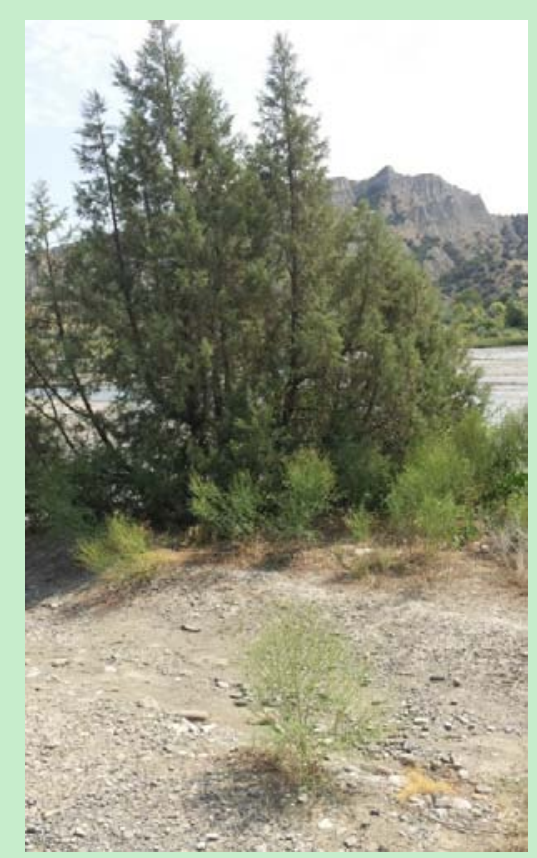

Fig. 1 Juniperus polycarpos K. Koch in Turianchai preserve.
$<0.25 \mathrm{~m}, 0.25-1 \mathrm{~m}, 1-5 \mathrm{~m}$ and $5 \mathrm{~m}>$ because individual size correlates notably with age in this species even when considering populations along environmental gradients. The close similarity between various plant sizes and age classes could be influenced by: the surrounding conditions where the individual plant grows and the density of individuals in the attitude. In the direction of taking account of these potential factors we also arbitrated the age of some individuals from Ref. [9] the presence or absence of reproductive organs and the consignment of dead wood (an individual of size $0.8 \mathrm{~m}$ showing reproductive structures were assigned as reproductive adult, an individual of size $4.0 \mathrm{~m}$ with a great amount of dead wood was assigned as senescent) [4]. Most of studied plants were reproductive adults and juveniles, $50 \%$ and $38 \%$ respectively (Table 1 ). This tendency shows the optimistic stabile position of Juniperus polycarpos K. Koch populationin in Turianchai preserve due to preservation events in this region. But we cannot say this for whole juniperus inhabitance in general, due to over-grazing and over-harvesting their quantity is declining and their protection is important.

\section{References}

[1] Gurbanov, E., and Rzaeva, A. A. 2017. "Biomorphological Analysis and Identification of Subspecies of Juniperus communis in Azerbaijan.” Asian Journal of Plant Science and Research 7 (3): 14-6.

[2] “Flora of Azerbaijan.” Publishing House of ANAS, Baku, Azerbaijan Vol I- VIII, Prilipko, 1950-61.

[3] Thomas, P. A., El Barghathi, M., and Palwart, A. 2007. "Biological Flora of the British Isles: Juniperus communis L.” J. Ecol. 95: 1404-40.

[4] Young, A., Boyle, T., and Brown, T. 1996. "The Population Genetic Consequences of Habitat Fragmentation of Plants.” Trends Ecol. E 11: 413-8.

[5] Clifton S. J., Ward L. K., and Ranner, D. S. 1997. "The Status of Juniper communis L. in North East England.” Biol. Conserv. 79: 67-77.

[6] Adams, R. P., and Schwarzbach. A. E. 2006. "A New Variety of Juniperus sabina from Mongolia J. Sabinavar Mongolenses.” Phytologia 88 (2): 179-85.

[7] Adams, R. P. 2004. “Juniperus deltoides, a New Species and Nomenclatural Notes on Juniperus polycarpos and J. Turcomanica (Cupressaceae).” 
in Turianchai Preserve (Azerbaijan Republic)

Phytologia 86: 49-53.

[8] Adams, R. P. 2011. The Junipers of the World: The Genus Juniperus, 3rd ed. Victoria, BC: Trafford Publ.

[9] Garco, D., Zamora, R., Hodar, J. A., and Gomez, J. M.
1999. "Age structure of Juniperus communis L. in the Iberian peninsula: Conservation of Remnant Populations in Mediterranean Mountains.” Biological Conservation 87: 215-20. 